\title{
ANÁLISE PSICOSSOCIAL DO POSICIONAMENTO DE ADOLESCENTES COM RELAÇÃO À VIOLÊNCIA POLICIAL
}

\author{
Ana Raquel Rosas Torres \\ Margareth Regina G.Veríssimo de Faria" \\ Juliany Gonçalves Guimarães" \\ Thalita Vargas Leite Martignoni ${ }^{\infty}$
}

RESUMO. O objetivo deste trabalho foi investigar os posicionamentos de estudantes do ensino médio, residentes na periferia de Goiânia, com relação ao uso de ações extrajudiciais pela polícia objetivando resolver um crime. Partimos do pressuposto que essas tomadas de posição estariam ancoradas em sistemas de crenças e atitudes sociais que regulariam nossas relações cotidianas. Assim, utilizamos as crenças e atitudes relacionadas com os Direitos Humanos, com a Democracia e com o Autoritarismo para analisar essas ancoragens. Participaram deste estudo 140 estudantes do ensino médio de uma escola pública da periferia de Goiânia. Os resultados demonstram a importância das atitudes e crenças com relação aos Direitos Humanos e à Democracia para a posição com relação às ações extrajudiciais. Esses resultados são discutidos ressaltando-se a importância de uma educação onde esses valores sejam incluídos.

Palavras-chave: violência policial, direitos humanos, democracia e autoritarismo.

\section{PSYCHOSOCIAL ANALYSES OF ADOLESCENTS' POSITIONING TOWARDS POLICE VIOLENCE}

\begin{abstract}
The objective of this work was to investigate high school students' positioning towards the use of violence by the police in order to solve a crime. Our starting point is that this positioning is anchored on systems of social beliefs and attitudes which regulate our daily relationships. Thus, we used social beliefs and attitudes related to Human Rights, Democracy and Authoritarianism in order to investigate those anchorages. The participants were 140 students high school students from a public school located in the perifery of Goiânia (Brazil). The results showed the importance of social beliefs and attitudes related to Human Rights and Democracy in order to understand students positioning related to police violence. These results are discussed stressing the importance of a kind of educational system where those values are included.
\end{abstract}

Key words: Police violence, human rights, democracy and authoritarianism.

\section{ANÁLISIS PSICO-SOCIAL DE POSICIONAMIENTO DE ADOLESCENTES CON RELACIÓN A LA VIOLENCIA POLICIAL}

RESUMEN. El objetivo de este trabajo fue el investigar los posicionamientos de estudiantes de la educación secundaria, residentes en la periferia de la ciudad de Goiânia (Brasil), con relación al uso de acciones extrajudiciales por la policía, con el objetivo resolver un crimen. Partimos de la suposición que esas tomas de posición estarían ancladas en sistemas de creencias y actitudes sociales que regularían nuestras relaciones cotidianas. De ese modo, utilizamos las creencias y actitudes relacionadas a los derechos humanos, a la democracia y al autoritarismo para analizar tales anclajes. Participaron de este estudio 140 estudiantes de la educación secundaria de una escuela pública de la periferia de la ciudad de Goiânia (Brasil). Los resultados demuestran la importancia de las actitudes y creencias con relación a los derechos humanos y a la democracia para la posición con relación a las acciones extrajudiciales. Esos resultados son discutidos resaltándose la importancia de una educación donde esos valores sean incluidos.

Palabras-clave: violencia policial, derechos humanos, democracia y autoritarismo.

* Doutora em Psicologia, docente do Programa de Pós-Graduação e da Graduação em Psicologia - Departamento de Psicologia da Universidade Católica de Goiás (UCG).

\# Mestre em Psicologia pela UCG, docente convidada do Departamento de Psicologia da UCG.

Il Mestre em Psicologia, docente do Departamento de Psicologia da UCG e Universidade Paulista (UNIP); docente do Departamento de Ciências Jurídicas (UNIP) e Faculdades Alves Faria (ALFA).

x Bacharel em Direito, Mestranda em Psicologia pela UCG. 
Há quase 15 anos, o Brasil assistiu à invasão do presídio Carandiru, em São Paulo, pela Polícia Militar daquele estado e que resultou na morte de 111 presos, muitos dos quais ainda aguardavam julgamento. $\mathrm{Na}$ época, a sociedade brasileira se viu dividida, pois muitos defendiam a ação da polícia afirmando que só assim a criminalidade começaria a diminuir. Esse apoio ficou claro, posteriormente, quando o Coronel Ubiratan Guimarães, que comandou a invasão do presídio, foi eleito deputado estadual por São Paulo. Mais recentemente, em fevereiro de 2006, esse coronel foi absolvido pelo Tribunal de Justiça de São Paulo de qualquer responsabilidade pelo ocorrido. Por outro lado, apesar da Justiça ter responsabilizado o Estado pelas mortes na maioria dos processos abertos pelos familiares dos mortos, apenas oito famílias de detentos começaram a receber o dinheiro das indenizações por danos morais.

Diante desse quadro, e de outros exemplos mais recentes de excessos cometidos pela polícia, que teoricamente visam combater a criminalidade, este trabalho tem como objetivo principal investigar $o$ posicionamento de jovens frente a esse tipo de ação policial. Essas ações, denominadas por León, Carneiro e Cruz (1999) de ações extrajudiciais, têm como característica principal o fato de violarem o Estado de Direito e, conseqüentemente, ignorarem também os direitos dos cidadãos comuns. No Brasil, segundo Gaspari (2002), o uso da força pelas corporações policiais ainda é uma herança do período da ditadura militar quando a concepção de segurança nacional estava ancorada em dois grandes temas: o primeiro era que, para a segurança da nação, tudo poderia ser feito e o segundo era que, em caso de perigo iminente, os militares poderiam intervir e assim salvaguardar a nossa pátria. Sendo assim, falar em violência policial significa necessariamente discutir direitos humanos, democracia e autoritarismo. Esses três temas estão deixando de ser exclusivos da ciência política ou da sociologia e estão cada vez mais presentes na psicologia social, pois, segundo Guimarães, Torres e Faria (2005), além de conceitos teóricos relacionados a formas de governo, eles representam também diferentes visões da organização da sociedade e da maneira como o indivíduo nela se insere. Assim sendo, eles são também conjuntos de crenças e valores sociais. É sob essa ótica que eles serão discutidos a seguir.

\section{DIREITOS HUMANOS: UMA UTOPIA POSSÍVEL?}

A Declaração Universal dos Direitos Humanos (DUDH), promulgada em 1948 pela Organização das
Nações Unidas (ONU), surgiu no bojo do final da Segunda Guerra Mundial e introduziu a chamada visão contemporânea dos direitos humanos. Segundo Piovesan (2005), essa visão tem duas características principais: a universalidade e a indivisibilidade. A universalidade diz respeito à extensão universal dos direitos humanos, pressupondo para isso que o homem é um ser essencialmente moral. Já a indivisibilidade relaciona-se ao fato que a DUDH colocou no mesmo patamar os direitos civis, políticos, econômicos, sociais e culturais. Ainda segundo Piovesan (2005), “a DUDH combina o discurso liberal e o discurso social da cidadania, conjugando o valor da liberdade ao valor da igualdade" (p. 45).

Bonavides (1993) considera que o valor da liberdade estaria traduzido nos direitos de primeira geração: direitos civis e políticos, tais como a liberdade e a propriedade privada, que foram afirmados como limites ao poder dos governantes dos Estados absolutistas. Já o valor da igualdade encontra-se nos direitos sociais e econômicos introduzidos pelo constitucionalismo social. Ainda uma terceira geração de direitos se destina à proteção de interesses do gênero humano, e não apenas de indivíduos ou grupos - tais como o direito à paz e ao meio ambiente. Contudo, Piovesan (2002) alerta que, nessa visão geracional dos direitos do homem, estes devem ser considerados como complementares e cumulativos, pois uma geração de direitos não exclui a outra, ao contrário, garante sua aplicabilidade.

Bobbio (2004) considera que proteção dos direitos de liberdade é dada pela ação negativa do Estado, que tem seu poder limitado. Já a proteção dos direitos sociais requer uma intervenção ativa do Estado, que ampliaria seu domínio. O exercício do poder, portanto, pode ser considerado benéfico ou maléfico, partindo de diferentes contextos históricos em que ocorreu.

Nesse sentido, Comparato (1999) reflete sobre a emancipação histórica do indivíduo, a partir das declarações de direitos, perante os grupos sociais a que sempre foi submetido. Segundo ele, a perda da proteção familiar, estamental ou religiosa tornou o indivíduo muito mais vulnerável às vicissitudes da vida. A sociedade liberal ofereceu-lhe, em troca, a segurança da legalidade, com a garantia de igualdade de todos perante a lei. Mas essa isonomia tornou-se inútil para a legião de trabalhadores que são compelidos a se empregarem nas empresas capitalistas, submetendo-se às leis do mercado.

Nos últimos anos a psicologia social vem se interessando cada vez mais pelos direitos humanos. O grupo liderado por Willem Doise, da Universidade de 
Genebra (Suíça), desde meados da década de 1990 muito tem publicado sobre esse tema. Tomados em conjunto, as pesquisas realizadas por esse grupo sobre as representações sociais a respeito da Declaração Universal dos Direitos Humanos mostram que os participantes dos mais diferentes países organizam os direitos em duas grandes categorias - direitos políticos e direitos econômicos (Doise, 1998; Doise \& Herrera 1994). Mas, isso não quer dizer que essas representações sociais são semelhantes em todos os países estudados. A heterogeneidade encontrada nesses resultados estava não ligada aos países per si, e sim com as pertenças sociais concretas dos participantes nos seus respectivos países de origem, relacionando-se diretamente com os seus posicionamentos políticoideológicos.

No Brasil, seguindo essa mesma linha de raciocínio, temos o trabalho de Pereira e Camino (2003) que mostra a importância do ativismo político dos participantes para o envolvimento na defesa dos direitos humanos. Além disso, esse trabalho mostra a importância da simpatia partidária para a avaliação que é feita sobre o envolvimento do governo brasileiro na luta em defesa dos direitos humanos, demonstrando assim, da mesma forma que os trabalhos de Doise discutidos anteriormente, a preponderância dos posicionamentos político-ideológicos na construção e organização das representações sociais dos direitos humanos.

Nos trabalhos de Pereira e Camino (2003) e Camino e cols. (2004), um resultado é de especial importância para nós. Ele diz respeito à importância das simpatias partidárias como pontos de ancoragem para a organização das representações sociais sobre os direitos humanos. Estes trabalhos mostram que o posicionamento no espectro direita-esquerda do partido político de simpatia se relaciona fortemente com a avaliação que é feita do envolvimento do governo brasileiro na luta pelos direitos humanos. Assim, simpatizantes de partidos localizados à direita acham que o governo está muito engajado nessa luta. Ao contrário, os simpatizantes de partidos localizados à esquerda dizem que o governo não tem feito 0 suficiente para garantir os direitos do povo brasileiro. No entanto, sabemos que no Brasil, pela própria organização do sistema partidário, a classificação direita-esquerda é problemática. Ela deveria refletir posicionamentos político-ideológicos claros e representativos dos conflitos existentes entre os diversos setores sociais que formam a sociedade brasileira. Mas, ao contrário, os partidos políticos brasileiros, embora representem diferentes setores, possuem cada vez mais discursos homogêneos, o que torna difícil distinguir quem é de direita ou de esquerda.

Diante desse contexto, optou-se, neste estudo, analisar especificamente dois grandes sistemas ideológicos - democracia e autoritarismo. A ideologia é aqui entendida como um "sistema simbólico interatuante de padrões de significados articulados (Geertz, 1978) que adquirem forma e existência nos signos criados por um grupo no curso de suas relações sociais" (Baktin, citado por Pereira \& Camino, 2003, p. 450). Sendo assim, ao mesmo tempo em que é construída no seio das relações sociais, ela também serve de pano de fundo dessas mesmas relações sociais.

Mas como os estudos sobre ideologias se inserem e se articulam com conceitos da psicologia social? De acordo com Camino, Lima e Torres (1997), para que ocorra essa articulação, a ideologia deveria ser estudada em três níveis de análise. No primeiro, estariam os sistemas de crenças explicativas e justificadoras da ordem social estabelecida, definindo o que é bom ou ruim, aceitável ou não. Contudo, essas crenças não seriam homogêneas e é essa heterogeneidade que permitiria o segundo nível de análise, que insere as ideologias no âmbito dos conflitos sociais, sejam eles explícitos, como no caso das guerras, ou implícitos, como no caso das injustiças sociais presentes na grande maioria das sociedades que não se encontram em guerra. Aqui estariam os mais diferentes tipos de ideologias: políticas (ex.: liberalismo, populismo), sociais (feminismo), entre outras. Esse nível também não seria homogêneo porque presume a existência de grupos sociais concretos e seus interesses específicos. E, mais uma vez, seria essa heterogeneidade que permitiria o terceiro nível de análise. Nesse último nível, a ideologia estaria relacionada às práticas e representações concretas desenvolvidas a partir dos conteúdos e interesses ideológicos dos grupos e instituições sociais. Resumindo então, no primeiro nível estariam os sistemas de crenças a respeito da organização da sociedade. No segundo nível, estariam as origens desses sistemas de crenças e no terceiro nível, suas conseqüências. Aqui, é importante ressaltar que esse modelo de análise não pressupõe relações causais e uni-direcionais. Mas a idéia que o norteia é que ele seria retro-alimentativo: os sistemas de crenças norteiam as práticas que, por sua vez, constroem os sistemas de crenças.

No presente trabalho, o que se procura investigar é justamente as relações entre a adesão a uma prática, no caso às ações extrajudiciais, e a adesão a três sistemas de crenças (direitos humanos, democracia e 
autoritarismo). A seguir, discutiremos os estudos sobre democracia e autoritarismo realizados no âmbito da psicologia social.

\section{DEMOCRACIA}

Segundo Da Costa (2000), existem duas concepções para o sentido de Democracia. A primeira refere-se a um sentido institucional no conceito de Democracia, predominante nas discussões acerca das condições de sua implementação e existência. Nesse sentido, caracteriza-se uma concepção minimalista, formal ou legal da Democracia, pois discute da perspectiva das condições da organização do Estado democrático e das instituições políticas que o caracterizam. Com algumas diferenciações, este entendimento da Democracia pode ser encontrado nos estudos de Schumpeter (1943), Dahal (1989, 1997), Sartori (1965) e Przeworski (1995, 1997). Por outro lado, o segundo aspecto engloba um sentido substantivo que surge nas teorizações que enfatizam não apenas os métodos ou meios pelos quais a Democracia é instituída, mas principalmente os aspectos relativos a seus fins e os ideais que a compõem. Caracteriza-se, então, como uma perspectiva maximalista ou holística que enfatiza o papel político e educativo da participação, estendida a todos os aspectos da vida social, ou seja, refere-se à participação igualitária na tomada de decisões. Essa concepção também pode ser denominada de Democracia Participativa. Com variações e divergências, esse conceito pode ser encontrado nas pesquisas de Pateman (1970, 1985), MacPherson (1977), Poulantzas (1980), Held (1987), Touraine $(1996,1997)$ e Giddens (1996).

Na primeira concepção, a Democracia pode ser definida como um padrão de organização do campo político da sociedade que se restringe a uma compreensão dos aspectos jurídico-institucionais da vida social; sua essência consiste na "representação de interesses" e na "garantia da liberdade". Na segunda concepção, a Democracia é entendida como um padrão social global, refletindo uma compreensão ampla da política que abrange todos os aspectos da vida social; sua essência reside na "participação ampla" e na "garantia de direitos e equidade" (Held, 1987; Lamounier, 1996; Pateman, 1970). Contudo, qualquer que seja o modelo de Democracia, formal ou participativa, um aspecto básico faz-se presente - o sentido normativo. A Democracia, além de ser um modo de organização e regulação da sociedade, é também um conjunto de normas, valores e crenças (Berger, 1997; Pereira, Torres \& Barros, 2004).

Então, como definir Democracia? No plano do ordenamento jurídico-institucional, a Democracia compreende a existência de independência e mútuo controle dos poderes do Estado, a realização de eleições, o pluralismo político, a representação e a participação das maiorias e minorias na gestão do Estado, o respeito aos direitos humanos e as liberdades fundamentais. Já no plano da implementação de ações práticas e de políticas de governo, a Democracia compreende a igualdade na administração das desigualdades na vida social e das diferenças de recursos e de poder que impedem a participação livre e igual dos cidadãos na vida política e civil, ou seja, a Democracia deve garantir a todos os cidadãos igualdade de condições para a vida social e para o exercício da cidadania. De acordo com Da Costa (2000), conclui-se, então, que a liberdade e igualdade são os atributos mais importantes para definir Democracia.

\section{AUTORITARISMO}

Segundo Lima (1997), a definição de democracia deve estar centrada no respeito e na tolerância à diversidade, seja ela étnica, cultural, social, política, religiosa ou econômica. Fernandes (citado por Lima, 1997) enfatizou que o conceito de autoritarismo é contrário à democracia. Trata-se de um conceito que designa tanto uma forma totalitária de governo ou conduta, quanto uma exageração da autoridade, interna à democracia ou externa a ela. Os governos dotados de regimes políticos autoritários preferem a autoridade governamental, minimizando o consenso, centralizando o poder em algumas pessoas ou alguns órgãos.

As concepções autoritárias destacam o princípio hierárquico e fundamentam-se na desigualdade natural ou social entre homens. Stoppino (citado por Lima, 1997) acreditava que as teorias sobre o autoritarismo podem ser organizadas em três perspectivas: a personalidade autoritária, o autoritarismo cognitivo e o autoritarismo da classe trabalhadora. De acordo com este autor, a personalidade autoritária investigada por Adorno, Frenkel-Brunswik, Levinson e Sanford (1950), é o resultado de um conjunto de traços: submissão, agressividade, crença alucinada nas autoridades, obediência para com os superiores, falta de consideração com os inferiores, rigidez e conformismo.

Contudo, o autoritarismo não pode ser considerado apenas uma atitude ou característica de 
personalidade, pois se trata de uma construção representacional das relações de poder. Segundo Lipset (1967) o autoritarismo da classe trabalhadora considera que na sociedade moderna as classes mais baixas são as mais autoritárias, são menos adeptas às liberdades civis e mais intolerantes com os desvios de conduta com relação aos códigos morais convencionais.

Posterior a Adorno e cols. (1950), Altemeyer conceitualizou o autoritarismo de acordo com três grandes constructos atitudinais: a agressão autoritária, a submissão autoritária e o conservadorismo (Altemeyer, 1981, 1988, 1996). Assim, a combinação destas três atitudes define a atitude mais conservadora.

Atualmente, Feldman (2003) sugere que a teoria sobre o autoritarismo deve abordar "o conflito entre a ordem social baseada na conformidade social e o desejo de maximizar a autonomia pessoal" (p. 66), ou seja, deve-se investigar a relação do autoritarismo com os valores sociais.

A partir das análises sobre democracia e autoritarismo, verifica-se que os Estados autoritários (que não efetivaram um Estado de Direito) fazem uso da força legitimada e realizam inúmeras modalidades de violência, restringindo os direitos dos cidadãos. No Brasil, tem-se, por um lado, a cultura policial rígida, autoritária e capaz de infringir a lei em nome da ordem pública e, por outro, a população que incentiva as ações violentas, principalmente quando é caracterizada ou está próxima da vítima. Nesse sentido, por exemplo, temos o estudo de Machado e Noronha (2002), realizado em um bairro popular de Salvador (Bahia), que mostra a ambigüidade dos moradores em relação à violência policial. Se por um lado, os entrevistados denunciam e rejeitam a violência da polícia contra membros de minorias sociais (negros, desempregados etc.), eles não só apóiam como defendem essa mesma violência quando dirigida a criminosos. Esses autores, ligados ao Núcleo de Estudos da Violência da Universidade de São Paulo", concluem que "a aprovação da violência policial é justificada pela distinção estabelecida pela população entre a violência ilegítima, cometida contra "nós", pessoas direitas, da violência legitima, cometidas contra "eles", os marginais" (p. 213).

Diante do exposto até aqui, este estudo tem como objetivo principal investigar os posicionamentos de estudantes do ensino médio residentes na periferia de Goiânia com relação ao uso de ações extrajudiciais pela polícia objetivando resolver um crime. Contudo, partimos do pressuposto que essas tomadas de posição

\footnotetext{
www.nevusp.org
}

não ocorrem num vácuo. Elas estariam ancoradas em sistemas de crenças e atitudes sociais que regulariam nossas relações cotidianas. Neste caso, utilizamos as crenças e atitudes relacionadas com os Direitos Humanos, com a Democracia e com o Autoritarismo.

\section{MÉTODO}

Cento e quarenta estudantes do ensino médio, do turno noturno, de uma escola pública da periferia de Goiânia participaram deste estudo. A idade média dos participantes é de 17,9 anos $(D P=4,2)$. Dos participantes, $32,1 \%$ eram homens, $57,1 \%$ mulheres e 10,7 não responderam essa questão. Essa escola está localizada próxima a uma grande ocupação urbana, ainda não legalizada pela Prefeitura de Goiânia. As ruas ao seu redor têm iluminação precária devido ao vandalismo contra a rede de iluminação, como por exemplo, jogar pedras para quebras as lâmpadas. A polícia é frequentemente chamada para resolver problemas de agressões entre os alunos e de tráfico de drogas nas suas proximidades.

O questionário utilizado era composto por duas seções. Na primeira, havia três escalas tipo Likert, variando de 1 (discordo) a 7 (concordo). A primeira escala versava sobre as atitudes dos participantes em relação aos direitos humanos e foi desenvolvida por Guimarães, Torres e Faria (2005) baseada e adaptada da escala de Diaz-Veizades, Widaman, Little e Gibbs (1995) e na DUDH. A segunda escala continha itens sobre as atitudes em relação aos valores democráticos e foi inicialmente desenvolvida por Lima (1997) e Pereira, Lima e Camino (2001) e posteriormente ampliada por Pereira, Torres e Barros (2004). A terceira e última escala era sobre o autoritarismo (Altemeyer, 1988, 1996), traduzida e adaptada para o Brasil pelo Grupo de Pesquisa em Processos Grupais da UCG (Barros, 2002).

$\mathrm{Na}$ segunda seção do questionário, era apresentado aos participantes o relato de um sequiestro cometido por cinco homens. Havia três versões da estória, sendo: a) na primeira $(n=47)$ era apresentado um cenário neutro onde não havia menção a ações policias violentas; b) na segunda $(n=44)$, denominado de violência policial psicológica, havia apenas a ameaça por parte dos policiais a um dos seqüestradores presos; c) na terceira $(n=49)$, chamada de violência policial concreta, os policiais colocavam o seqüestrador em uma situação de perigo, esperando que ele colaborasse com a investigação denunciando os demais. A lógica desses cenários é o aumento progressivo da violência cometida pelos policiais 
à medida que aumenta também a violência cometida pelos seqüestradores contra a vítima (um homem de 55 anos e bem sucedido), tendo assim, talvez, uma justificativa para essas ações "coercitivas". Porém, o desfecho da estória era igual em todas as condições: após a prisão de um dos suspeitos, ele confessou sua participação no crime, mas não deu nenhum detalhe sobre os outros participantes. A estória termina enfatizando que o crime foi resolvido graças às investigações que estavam sendo feitas. Em seguida, havia uma questão, em formato Likert, perguntando da sua concordância com aquele tipo de ação policial. Esse procedimento, conhecido como priming $^{2}$, possui duas idéias norteadoras: a) ao utilizarmos como vítima da violência criminosa "um homem de 55 anos bem-sucedido" tínhamos como objetivo deixar claro para os participantes que esse personagem não pertencia à comunidade deles, era uma pessoa desconhecida, com a qual eles não tinham nenhum tipo de relação. Esse cuidado justifica-se, pois como demonstrado por Milgram (1965), a proximidade física ou afetiva da vítima de um infortúnio influencia nos julgamentos e na obediência à autoridade (para uma revisão desse efeito ver Blass, 2000; Zimbardo, Maslach \& Haney, 2000); b) ao enfatizarmos que o crime foi resolvido graças às investigações e não devido ao uso da violência policial contra os criminosos, objetivávamos explicitar que esse procedimento é ineficaz para o combate a criminalidade, não dando assim, uma justificativa para os participantes aceitálo.

Os questionários foram distribuídos aleatoriamente e respondidos individualmente em sala de aula. Após a aplicação, foi explicado aos participantes qual era o objetivo deste trabalho.

\section{RESULTADOS}

Os resultados serão apresentados em duas seções. $\mathrm{Na}$ primeira, apresentam-se as características psicométricas das escalas utilizadas e, em seguida, são apresentadas as análises a respeito do posicionamento dos participantes frente à ação policial.

\section{Características Psicométricas das Escalas Utilizadas}

As três escalas utilizadas foram submetidas a dois tipos de análises estatísticas. Primeiramente,

2 O priming explica como um conhecimento ativado recentemente influencia no desempenho de uma tarefa subseqüiente (para uma revisão ver Fiske \& Morling, 1995; Higgens, Bargh \& Lombardi, 1985). elas foram submetidas à análise fatorial dos componentes principais (PCA) a fim de investigarmos a validade do construto. Essa técnica estatística objetiva descobrir a estrutura de um conjunto de variáveis, no nosso caso, os itens de cada escala, a partir das correlações existentes entre eles. Em seguida, foram extraídos os respectivos Alphas de Cronbach. Pasquali (2003) afirma que esse coeficiente geral reflete o grau de covariância dos itens entre si, indicando a consistência interna da escala.

Iniciando pela escala das atitudes em relação aos direitos humanos, os resultados indicam que apenas um fator foi suficiente para organizar seus itens. Este fator explica $15,44 \%$ da variância. Sua medida de adequabilidade (KMO) foi de 0,60 e o valor próprio de 6,45 , o que é considerado significativo uma vez que é maior que 1 . O coeficiente de fidedignidade desse fator é de 0,74 , o que também é considerado como aceitável. A média dessa escala é de $5,29(D P=0,45)$, o que indica uma atitude mais favorável aos direitos humanos.

Os resultados da análise fatorial da escala dos valores democráticos demonstram que um único fator explica $18,92 \%$ da variância e cujo valor próprio é de 6,09 . Sua medida de adequabilidade (KMO) é de 0,61 e o Alpha de Cronbach é de 0,83. Todos esses resultados estão dentro dos parâmetros aceitáveis estatisticamente. Esta escala tem média igual a 4,78 $(D P=0,67)$, indicando uma tendência à aceitação dos valores democráticos.

A análise fatorial dos itens da escala de autoritarismo resultou em único fator, diferentemente do encontrado por Guimarães, Torres e Faria (2005). Esse fator explica $17,83 \%$ da variância, possui o valor próprio de 5,35 e medida de adequabilidade (KMO) igual a 0,62 . O coeficiente de fidedignidade dessa escala é de 0,81 . Sua média é de $3,77(D P=0,69)$, o que significa que existe uma tendência à rejeição ao autoritarismo.

\section{Análise do Posicionamento frente à Ação Policial}

Aqui, foram utilizadas duas técnicas estatísticas. Primeiramente, calculamos a análise de variância (ANOVA) dos níveis de concordância com a ação policial em função do tipo de cenário apresentado. Esta técnica objetiva investigar se a concordância com a ação policial varia de acordo com o cenário apresentado. Em seguida, utilizou-se a análise de regressão múltipla para investigar a influência das atitudes positivas em relação aos 
direitos humanos, a aceitação dos valores democráticos e a rejeição do autoritarismo sobre os níveis de concordância com a ação policial. Este procedimento estatístico analisa a dependência funcional entre as 3 variáveis independentes e a variável dependente. Aqui é importante esclarecer que, embora nesse tipo de análise se utilize os termos "variável dependente" e "variáveis independentes", isso não implica necessariamente numa relação de causalidade (Maroco, 2003).

Iniciando nossas análises pelos resultados das ANOVAS das três escalas, temos que não existe nenhuma diferença estatisticamente significativa. Ou seja, os graus de adesão aos direitos humanos $(F=2,30)$, aos valores democráticos $(F=0,06)$ e de rejeição ao autoritarismo $(F=1,06)$ não variam de acordo com o cenário. De fato, esse era o resultado esperado uma vez que os participantes responderam as escalas antes de lerem os cenários.

Por outro lado, a ANOVA do nível de concordância com a ação policial demonstrou $\mathrm{O}$ impacto das diferenças nos cenários nessa variável. Assim, temos (Tabela 1) que, na medida em que a violência cometida pelos seqüestradores contra a vítima aumenta, mais os participantes vão concordar com a ação policial.

Tabela 1. Médias, Desvios Padrões (entre parênteses) e Teste Estatístico da Concordância com a Ação Policial em Função do Tipo de Cenário.

\begin{tabular}{ccccccc}
\hline & \multicolumn{3}{c}{ Tipo de Cenário } & \multicolumn{3}{c}{ Teste Estatístico } \\
\cline { 2 - 7 } & Carta & Telefonema Mutilação & $\boldsymbol{F}$ & $\boldsymbol{g} \boldsymbol{~}$ & $\boldsymbol{p}<$ \\
\cline { 2 - 7 } Concordância & $3,59_{\mathrm{a}}$ & $4,46_{\mathrm{b}}$ & $6,10_{\mathrm{c}}$ & \multirow{2}{*}{68,57} & 2,136 & 0,001 \\
& $(1,27)$ & $(0,87)$ & $(0,98)$ & & & \\
\hline
\end{tabular}

Nota. As médias que não compartilham o mesmo subscrito representam diferenças significativas a $p<0,05$ no teste de Scheffé.

Em seguida, foram realizados três conjuntos de Regressões Múltiplas, uma para cada tipo de cenário. Os resultados do cenário 1 (Cenário Neutro) mostram que nenhuma das variáveis antecedentes alcançou níveis de significância estatística, ou seja, o posicionamento dos estudantes em relação à ação policial não é explicado por nenhuma das variáveis estudadas. Já a análise de regressão do cenário 2 (Violência Policial Psicológica) mostra que apenas as atitudes favoráveis aos direitos humanos explicam o posicionamento em relação à ação policial (Tabela 2). Aqui, quanto mais positivas forem as atitudes, menos os participantes concordam com a ação policial. Essa variável sozinha explica $60 \%$ da variância da aceitação da ação policial.
TABELA 2. Regressão Múltipla, pelo Método Stepwise, Concordância com a Ação Policial tendo com Variáveis Antecedentes as Atitudes em Relação aos Direitos Humanos, a Adesão aos Valores Democráticos e a Rejeição ao Autoritarismo.

\begin{tabular}{lllllll}
\hline \multirow{2}{*}{ Variáveis antecedentes } & \multicolumn{4}{c}{ Concordância com a Ação Policial } \\
\cline { 2 - 6 } & \multicolumn{2}{c}{$\begin{array}{c}\text { Cenário 2 } \\
\text { Telefonema }\end{array}$} & \multicolumn{2}{c}{$\begin{array}{c}\text { Cenário 3 } \\
\text { Mutilação }\end{array}$} \\
\cline { 2 - 6 } & Beta & $\boldsymbol{t}$ & $\boldsymbol{p}<$ & Beta & $\boldsymbol{t}$ & $\boldsymbol{p}<$ \\
\hline Direitos Humanos & $-0,80$ & $-3,82$ & 0,001 & & & \\
Democracia & & & & & & \\
& & & $-0,71$ & $-3,39$ & 0,001 \\
\hline Coeficiente de Regressão & $R=0,84$ & & $R=0,71$ & \\
Variância Explicada & $R^{2}=0,65 ; R_{\text {Ajustado }}^{2}=0,60$ & $R^{2}=0,51 ; R_{\text {Ajustado }}^{2}=0,47$ \\
Significância do Modelo & $F(1 / 43)=14,60 ; p<0,001$ & $F(1 / 48)=11,51 ; p<0,001$ \\
\hline
\end{tabular}

Finalmente, a análise de regressão do cenário 3 (Violência Policial Concreta) mostra que apenas a adesão aos valores democráticos explica o posicionamento dos participantes. Nesse caso, e seguindo os resultados do cenário 2, quanto maior for a adesão aos valores democráticos, menor é concordância com a ação policial. Essa variável sozinha explica $47 \%$ da variância dos níveis de aceitação da ação da polícia.

\section{DISCUSSÃO}

Este trabalho teve como objetivo principal analisar as tomadas de posições de jovens estudantes do ensino médio de Goiânia em relação a uma ação policial considerada extrajudicial. Para tanto, utilizou-se procedimento semelhante ao utilizado por Guimarães, Torres e Faria (2005) no qual era apresentado ao participante um cenário que descreve uma ação policial extrajudicial usada na tentativa de resolver um crime. A lógica desse procedimento é investigar se, diante de uma justificativa, o participante aceita o uso desse tipo de ação policial. A justificativa, no caso, se refere à agressão sofrida pela vítima do crime. O pressuposto teórico desse procedimento é que tal posicionamento estaria relacionado àquilo que nós chamamos de variáveis pré-existentes, e que estariam no âmbito de uma esfera política. Neste estudo, da mesma forma que em Guimarães, Torres e Faria (2005), utilizamos as atitudes em relação aos direitos humanos, a adesão aos valores democráticos e as atitudes em relação ao autoritarismo.

Tomados em conjunto, os resultados mostram que, diferentemente do encontrado em Guimarães, Torres e Faria (2005), na medida em que a violência contra a vítima do crime aumentava, 
aumentava também a aceitação da ação policial. Ou seja, aqui, diante de uma justificativa, os participantes aceitavam um tipo de ação policial ilegal que coloca em risco a organização democrática do Estado brasileiro. No estudo de Guimarães e cols. (2005), feito com policiais militares, os participantes não aceitaram a ação extrajudicial, independente da justificativa dada. Estes autores concluem que os policiais militares responderam conforme uma norma social que condena as ações extrajudiciais, já que trabalham para combater a violência social e não para contribuir para seu crescimento. Já os participantes deste estudo, da mesma forma que no estudo de Machado e Noronha (2002), aceitaram a ação da polícia. Ou seja, desde que a violência policial seja dirigida aos marginais, ela é vista como algo necessário que trará segurança para a comunidade. Ressalte-se que tanto o estudo de Machado e Noronha (2002) como o nosso foram realizados em bairros pobres, da periferia de grandes cidades, onde a maioria dos moradores não tem acesso às necessidades básicas, direitos deles, como por exemplo, saneamento, iluminação e segurança públicas e onde os índices de desemprego são altos. Estes fatores mostram um outro lado da violência policial ainda mais perverso, pois são eles, os membros de minorias sociais, que são as maiores vítimas das ações-extrajudiciais das polícias militares, como demonstram os estudos realizados pelo Núcleo de Estudos da Violência da Universidade de São Paulo. Assim, essas pessoas se tornam ao mesmo tempo vítimas e defensoras desse tipo de ação policial. As afirmações de Chevigny (1995) também auxiliam na compreensão do apoio à violência policial das camadas mais pobres da população. Para este autor, nos bairros periféricos das grandes cidades, frequentemente o policiamento inexiste ou quando existe, é ineficiente. Isso fomentaria na população os sentimentos de insegurança, desamparo e falta de controle sobre a criminalidade, o que, por sua vez, levaria ela própria a apoiar os excessos da polícia contra pessoas que comentem delitos grandes ou pequenos como forma de proteção contra a insegurança. Nessa mesma direção, León, Carneiro e Cruz (1999) afirmam que o problema do apoio da população às ações extrajudiciais da polícia brasileira é reflexo da ausência, ou da percepção da ausência, de políticas públicas eficazes para o combate à criminalidade. Assim, a sociedade brasileira se encontra diante de um círculo vicioso e perverso: a ausência da polícia aumenta a criminalidade e a população começa a defender que para combatê-la, a polícia pode usar de violência. Ou seja, práticas autoritárias começam a ser vistas como garantias da organização do Estado de Direito.

$\mathrm{O}$ segundo aspecto sobre os resultados aqui encontrados que merece ser discutido refere-se ao fato que as relações entre as variáveis pré-existentes e o posicionamento dos participantes mudavam de acordo com o cenário. No primeiro, não houve nenhum tipo de relação. No segundo, as atitudes favoráveis aos direitos humanos explicavam o posicionamento e, no terceiro, foi a vez da adesão aos valores democráticos. De acordo com Doise, Clemence e Lorenzi-Cioldi (1993), de uma maneira geral, as tomadas de decisões das pessoas se encontram ancoradas nas suas pertenças sociais, em sistemas de crenças etc. Dessa forma, os posicionamentos individuais não seriam produtos do mero processamento cognitivo, mas eles seriam construídos dentro de grandes matrizes ideológicas, religiosas, políticas etc. Concebendo os posicionamentos individuais a partir dessa perspectiva, podemos inferir que, de fato, as diferenças nos resultados seriam mais uma questão de ênfase do que de contradições. Assim, inicialmente, a questão dos Direitos Humanos ficou mais enfatizada, depois, no cenário que envolvia maior grau de violência, foi a Democracia. Contudo, de fato, esses dois aspectos têm igual importância para a manutenção do Estado de Direito.

Finalmente, gostaríamos de ressaltar que os resultados deste trabalho e de outros semelhantes aqui citados devem subsidiar o debate na sociedade e, em especial, dentro das escolas, a respeito de questões ligadas à democracia e da importância do respeito dos Direitos Humanos para sua existência. Sem esse debate, de primordial importância na contemporaneidade para o Brasil, e sem políticas públicas eficazes no combate as injustiças sociais, o risco da barbárie é grande. E não é esse o legado que devemos deixar para as gerações futuras.

\section{REFERÊNCIAS}

Adorno, T. W., Frenkel-Brunswik, E., Levinson, D. J. \& Sanford, R. N. (1950). The authoritarian personality. New York: John Wiley \& Sons.

Altemeyer, B. (1981). Right-wing authoritarianism. Manitoba: University.

Altemeyer, B. (1988). Enemies of Freedom. San Francisco: JosseyBass. 
Altemeyer, B. (1996). The authoritarian specter. Cambridge: Harvard University.

Barros, T. S. (2002). 11 de setembro de 2001: atribuições de causalidade e suas ancoragens em sistemas de valores e em atitudes políticas dos estudantes universitários de Goiânia. Dissertação de Mestrado Não-Publicada, Programa de PósGraduação em Psicologia, Universidade Católica de Goiás, Goiania.

Berger, P. L. (1997). Democracia e orientação espiritual: transmissão de sentidos na sociedade civil. Em W. Weidenfeld, O futuro da Democracia: projetos para o século XXI. São Paulo: Fundação Konrad-Adenauer-Stiftung.

Blass, T. (2000). The Milgram paradigm after 35 years: Some things we now know about obedience to authority. In T. Blass (Ed.), Obedience do authority: Current perspective on the Milgram paradigm (pp. 35-59). Mahwah: Lawrence Erlbaum.

Bobbio, N. (2004). A era dos direitos. Rio de Janeiro: Elsevier.

Bonavides, P. (1993). Curso de Direito Constitucional. São Paulo: Malheiros.

Camino, L., Lima, M. E., \& Torres, A. R. R. (1997). Ideologia e espaço político. Em L. Lhullier \& S. Sandoval (Orgs.), Estudos sobre comportamento político (pp. 87-105). Florianópolis.

Camino, C. S., Caminho, L., Pereira, C. \& Paz, M. (2004). Moral, direitos humanos e participação social. Estudos de Psicologia, 9, 25-34.

Chevigny, P. (1995). The edge of the knife: Police violence in the Americas. Nova York: The New.

Comparato, F. K. (1999). A Afirmação Histórica dos Direitos Humanos. São Paulo: Saraiva.

Da Costa, J. B. (2000). Visões Sociais de Democracia: um estudo psicossociológico dos significados de Democracia. Tese de Doutorado Não-Publicada, Programa de Pós-Graduação em Psicologia Social, Pontifícia Universidade Católica de São Paulo, São Paulo.

Dahal, R. A. (1989). Democracy and its Critics. New Haven: Yale University.

Dahal, R. A. (1997). Poliarquia. São Paulo: EDUSP.

Diaz-Veizades, J., Widaman, K. F., Little, T. D. \& Gibbs, K. W. (1995). The measurement and structure of human rights attitudes. Journal of Social Psychology, 135, 313-328.

Doise, W. (1998). Social psychology and human rights. European Review, 6, 349-355.

Doise, W., Clemence, A., \& Lorenzi-Cioldi, F. (1993). The quantitative analysis of social representations. Hempel Hempstead: Harvester Wheatsheaf.

Doise, W., \& Herrera, M. (1994). Déclaration universelle et représentations sociales des droits de l'homme: Une étude à Genève. Revue Internationale de Psychologie Sociale, 4, 87107.

Feldman, S. (2003). Enforcing social comformity: A theory of authoritarism. Political Psychology, 24(1), 41-74.

Fiske, S. T. \& Morling, B. A. (1995). Priming. Em A. S. R. Manstead \& M. Hewstone (Eds.), The Blackwell encyclopedia of social psychology. Oxford: Blackwell.

Gaspari, E. (2002). A ditadura escancarada. São Paulo: Companhia das Letras.
Gertz, C. (1978). Interpretação das culturas. Rio de Janeiro: Zahar

Giddens, A. (1996). Para além da esquerda e da direita. São Paulo: UNESP.

Guimarães, J. G., Torres, A. R. R., \& Faria, M. V. de. (2005). Democracia e Violência Policial: o caso da Polícia Militar. Psicologia em Estudo, 10(2), 165-173.

Held, D. (1987). Modelos de Democracia. Belo Horizonte: Paidéia.

Higgens, E. T., Bargh, J. A. \& Lombardi, W. (1985). Nature of priming effects on categorization. Journal of Experimental Psychology: Learning, Memory, and Cogntion, 11(1), 59-69.

Lamounier, B. (1996). A Democracia brasileira no limiar do século 21. São Paulo: Fundação Konrad-Adenauer-Stiftung.

León, B. R., Carneiro, P. L., \& Cruz, J. M. (1999). O apoio dos cidadãos à ação extrajudicial da polícia no Brasil, em El Salvador e na Venezuela. Em D. C. Pandolfi, J. M. de Carvalho, L. P. Carneiro, \& M. Grynszpan (Orgs.), Cidadania, justiça e violência (pp. 117-127). Rio de Janeiro: Fundação Getúlio Vargas.

Lima, M. E. O. (1997). Valores, participação política, atitudes face a democracia e ao autoritarismo: uma análise da socialização política dos universitários da Paraíba. Dissertação de Mestrado Não-Publicada, Programa de PósGraduação em Psicologia, Universidade Federal da Paraíba, João Pessoa.

Lipset, S. M. (1967). O homem político. Rio de Janeiro: Zahar.

MacPherson, C. B. (1977). The life and times of Liberal Democracy. Oxford: Oxford Univesity.

Machado, E. P. \& Noronha, C. V. (2002). A polícia dos pobres: violência policial em classes populares urbanas. Sociologias, 4(7), 188-221.

Maroco, J. (2003). Análise Estatística com utilização do SPSS. Lisboa: Silabo.

Milgram, S. (1965). Some conditions of obedience and desobedinece to authority. Human Relations, 18, 56-76.

Pasquali, L. (2003). Psicometria: teoria dos testes na Psicologia e na Educação. Rio de Janeiro: Vozes.

Pateman, C. (1970). Participation and democratic theory. Cambridge: Cambridge University.

Pereira, C. \& Camino, L. (2003). Representações sociais, envolvimento nos Direitos Humanos e ideologia política em estudantes universitários de João Pessoa. Psicologia: Reflexão \& Crítica, 16(3), 447-460.

Pereira, C., Lima, M. E. \& Camino, L. (2001). Sistemas de valores e atitudes democráticas de estudantes universitários de João Pessoa. Psicologia: reflexão \& crítica, 14, 167-190.

Pereira, C., Torres, A. R. R. \& Barros, T. S. (2004). Sistemas de valores e atitudes democráticas de estudantes universitários. Psicologia: teoria e pesquisa, 20(1), 001-010.

Piovesan, F. (2002). Direitos Humanos e o Direito Constitucional Internacional. São Paulo: Max Limonad.

Piovesan, F. (2005). Ações Afirmativas da Perspectiva dos Direitos Humanos. Cadernos de Pesquisa, 35(124), 43-55.

Poulantzas, N. (1980). State, Power, Socialism. Londres: Verso/New Left Books. 
Przeworski, A. (1995). Democracia y Mercado. Cambridge: Cambridge University.

Przeworski, A. (1997). Una defensa de la concpción minimalista de la Democracia. Revista Mexicana de Sociologia, 59(3), 336

Sartori, G. (1965). Democratic theory. Detroit: Wayne State University.

Schumpeter, J. (1943). Capitalism, Socialism, and Democracy. London: George Allen \& Unwin.

Touraine, A. (1996). O que é Democracia? Petrópolis: Vozes.

Touraine, A. (1997). Poderimos vivir juntos? Buenos Aires: Fondo de Cultura Económica.
Zimbardo, P.G., Maslach, C. \& Haney, C. (2000). Reflections on the Stanford Prison Experiment: Genesis, transformations, consequences. In T. Blass (Ed.), Obedience do authority: Current perspective on the Milgram paradigm (pp. 193-237). Mahwah: Lawrence Erlbaum.

Recebido em 04/04/2006 Aceito em 21/12/2006

Endereço para correspondência: Ana Raquel Rosas Torres. Departamento de Psicologia, Universidade Católica de Goiás, Centro Av. Universitária, 1440, Setor Universitário, 74605-010, Goiânia-Goiás. E-mail: arr.torres@gmail.com 